\title{
Tooth surface deviation and mesh analysis of beveloid gears with parallel axis considering machine tool adjustment errors
}

\author{
Xingyu YANG*, Chaosheng SONG*, Caichao ZHU* and Siyuan LIU* \\ *The State Key Laboratory of Mechanical Transmissions, Chongqing University \\ No. 174 Shazhengjie, Shapingba, Chongqing 400044, China \\ E-mail: chaoshengsong@hotmail.com
}

Received: 4 May 2018; Revised: 25 June 2018; Accepted: 9 July 2018

\begin{abstract}
The mathematical beveloid gear tooth surface model considering machine tool adjustment errors was derived. The definition and calculation process of tooth surface deviations along the tooth trace and profile directions for beveloid gear were proposed. Also, the solid model and the finite element mesh model of a paralleled beveloid gear pair were developed. Then, the effects of the machine tool adjustment errors including independent helix angle error, independent cone angle error and combined helix and cone angle errors on tooth surface deviation and contact characteristics were investigated. Results show that all the machine tool adjustment errors cause an incremental trend for the tooth profile and tooth trace deviations. And positive errors have the opposite impact on the surface deviation compared with the negative errors. The independent helix angle error has a stronger impact on the tooth surface deviations than the independent cone angle error and combined angle errors. Also, the tooth surface deviations caused by the independent helix angle error, independent cone angle error and combined angle errors have the similar magnitude level as the tooth surface modifications. All the independent helix angle error, independent cone angle error and combined angle errors tend to have deteriorative effects on the mesh characteristics, making edge contact worse, decreasing the contact area, increasing the contact pressure and the transmission error. The independent helix angle error has the strongest impact both on the contact pattern and transmission error, which is similar to the impact on the tooth surface deviations. However, the independent cone angle error shows less effects on the mesh characteristics. Thus the machine tool adjustment errors should be strictly controlled especially for the helix angle error during manufacturing.
\end{abstract}

Keywords : Beveloid gear, Parallel axis, Machine tool adjustment errors, Tooth profile deviation, Tooth trace deviation, Mesh characteristics

\section{Introduction}

Beveloid gear, which has a varying profile shift coefficient along the tooth width direction, can be used in backlashfree transmission with parallel axes due to the design concept with opposed cone angles to facilitate the minimalization of backlash by adjusting their axial position. And, this type of gearing can be applied in steering transmission, lowbacklash planetary gears for robots and other precise transmission systems (Bürkle et al., 1993, Somschor et al., 1996). Thus, the precise design for the beveloid gear tooth surface is highly demanded. However, some unavoidable errors including the machine tool deformation error, gear blank and machine tool installation errors, which can be synthesized to the machine tool adjustment errors, exist during the beveloid gear manufacturing process. Also, they can deteriorate the subsequent tooth contact characteristics. Therefore, it is significant to analyze the impact of machine tool adjustment errors on tooth surface deviations and mesh characteristics of beveloid gears with parallel axis.

For decades, researchers conducted the design, manufacturing, tooth contact analysis, measurement and experiment on the beveloid gears with different installation conditions. The macro-geometry design consider the approximate line contact constraint was investigated to overcome the low surface durability due to the theoretical point contact (Koyama et al, 2005, Wu et al.,2009, Zhu et al., 2012) for beveloid gears with non-parallel axes. Then, the tooth undercutting equations for beveloid gear were derived and two methods, which are tooth design with asymmetrical normal pressure 
angle and varying working depth, to avoid the undercutting were proposed (Liu et al., 2001). Then analytical and numerical tooth contact analysis were selected to study the contact characteristics for this type of gearing (Liu et al., 2002, Wu et al., 2009, Do et al., 2015). For the micro-geometry design, Morikawa performed the mesh efficiency analysis considering the tooth surface modification for the spatial beveloid gearing used in FR-4WD transfer (Morikawa et al., 2014). Also the results from this group show that the crowning in profile direction and reverse crowning in tooth trace direction can improve the contact behaviors (Morikawa et al., 2015). Brecher presented an analytical-empiric method for the root carrying capacity and conducted the fatigue tests to evaluate the theoretical results (Brecher et al., 2014). Also, he proposed a micro-geometry design method considering the tolerance fields to optimize the contact characteristics (Brecher et al., 2016). The parametric study for contact characteristics of the crossed beveloid gear pair by an assumed rack cutter with parabolic shape was performed (Ni et al., 2017). For beveloid gears with parallel axes, Hori presented a synthesis method to derive the tooth profile of external/internal beveloid gears which engage with conventional cylindrical gear (Hori et al., 1998). Ni presented a pitch cone based geometry design procedure and studied the influences of cone angle, load and misalignments on the mesh behaviors (Ni et al., 2016). Chen presented a processing method for internal beveloid gear and studied the contact characteristics based on a finite element mesh model for paralleled beveloid gear pair (Chen et al., 2017). For the studies mentioned above, the macro and micro geometry parameters, load and misalignments for the gear pair are mainly considered to investigate the mesh behaviors for beveloid gearing. However, the machine tool adjustment errors were not considered for the conventional mathematical model for the beveloid gear tooth surface. Also, compared to the conventional cylindrical gear and other spatial gearing, very limited research has been performed at the tooth surface deviation analysis and the detailed effects on the mesh for beveloid gear pair with parallel axis.

In this paper, a mathematical model for the beveloid gear tooth surface considering the machine tool adjustment errors based on the theory of hobbing machining was derived. The calculation approach of tooth profile and trace deviations was proposed. The solid geometry model and the finite element mesh model were developed. Then, the influences of the machine tool adjustment errors including independent helix angle error, independent cone angle error and combined helix and cone angle errors on the tooth surface deviation and mesh characteristics were investigated.

\section{Beveloid gear model considering machine tool adjustment errors}

According to the inclining work-arbor taper hobbing manufacturing process of beveloid gear (Mitome, 1986), the synthesized machine tool adjustment errors can be divided into the helix angle and cone angle errors. The definition for the typical machine tool adjustment errors are shown in Fig.1.

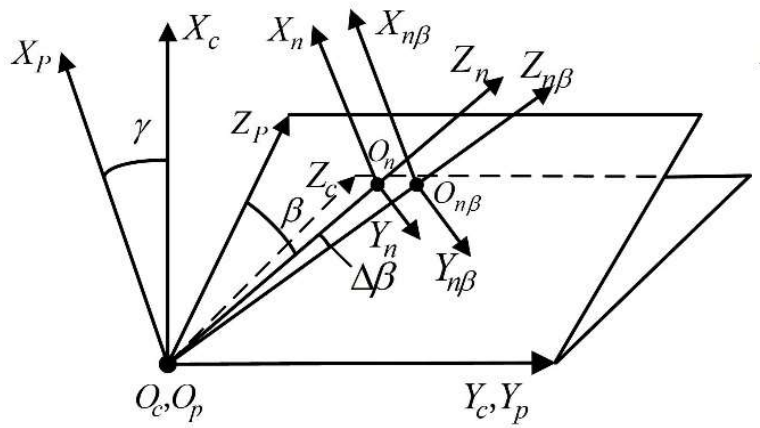

(a) Helix angle error

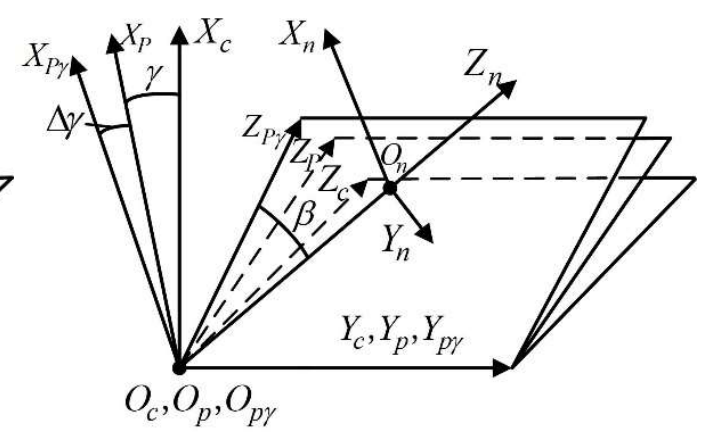

(b) Cone angle error

Fig.1 Rack cutter coordinate systems

The helix and cone angles are denoted by $\beta$ and $\gamma$, respectively. The plane axode coordinate system is denoted by $S_{c}\left(x_{c}, y_{c}, z_{c}\right) . S_{p}\left(x_{p}, y_{p}, z_{p}\right)$ and $S_{n}\left(x_{n}, y_{n}, z_{n}\right)$ are the auxiliary coordinate systems for the rack cutter. $x_{n}-y_{n}$ plane and $y_{p}-z_{p}$ plane represent the normal section without helix angle error and the transverse plane without cone angle error of the rack cutter, respectively. $S_{n \beta}\left(x_{n \beta}, y_{n \beta}, z_{n \beta}\right)$ represents the helix angle error coordinate system. The helix angle error can be represented by the angle $\Delta \beta$ between $O_{p} O_{n}$ and $O_{p} O_{n \beta}$ in $y_{p}-z_{p}$ plane. As shown in Fig.1(b), $S_{p \gamma}\left(x_{p \gamma}, y_{p \gamma}, z_{p \gamma}\right)$ represents the cone angle error coordinate system and the cone angle error can be represented as the angle $\Delta \gamma$ between axis $x_{p}$ and $x_{p \gamma}$. Considering the helix angle error and cone angle error 
simultaneously, the coordinates between the rack cutter and the gear blank can be shown in Fig.2.

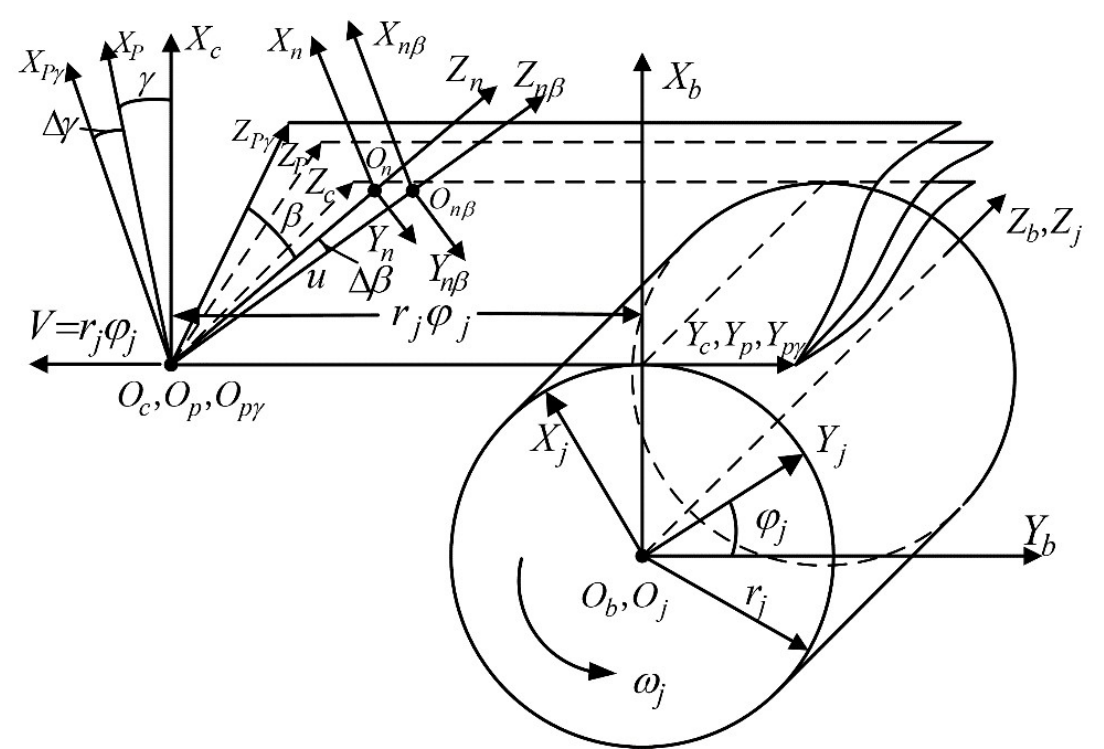

Fig.2 Coordinates for manufacturing process with machine tool adjustment errors

$S_{b}\left(x_{b}, y_{b}, z_{b}\right)$ denotes the globe coordinate system and $S_{j}\left(x_{j}, y_{j}, z_{j}\right)$ denotes the coordinate system fixed to the gear blank. $r_{j}$ denotes the reference pitch circle radius and $\varphi_{j}$ denotes the rotation angle for the processing. For the simulation along the tooth trace direction, the normal section of the rack cutter moves along the straight line $O_{p \gamma} O_{n \beta}$, and $u$ denotes the distance from origin $O_{p \gamma}$ to $O_{n \beta}$. As shown in Fig.3, the rack cutter is defined in coordinate system $S_{n \beta} . P_{n}$ and $p_{c}$ denote the gear diametral pitch and the circular pitch, respectively. $\alpha_{n}$ denotes the pressure angle. $c_{n}$ denotes the clearance coefficient. The normal cross section can be divided into left and right parts and each part is consisted of three segments, line segment $M_{0}^{r(l)} M_{1}^{r(l)}$, arc segment $M_{1}^{r(l)} M_{2}^{(l)}$, and line segment $M_{2}^{r(l)} M_{3}^{r(l)}$.

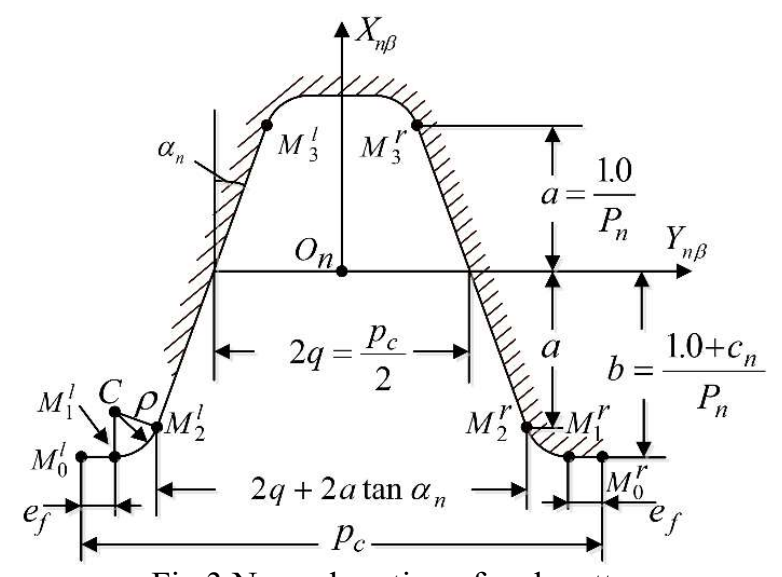

Fig.3 Normal section of rack cutter

According to the spatial gearing theory, the rack cutter can be expressed mathematically in $S_{c}$ by

$$
R_{c}=M_{c, p} M_{p, p \gamma} M_{p \gamma, n} M_{n, n \beta} R_{n \beta}
$$

Where $R_{c}$ represents the position vector in $S_{c}$ for the cutter and $R_{n \beta}$ represents the position vector in $S_{n}$ for the normal section of cutter. $M_{c, p}, M_{p, p \gamma}, M_{p \gamma, n}$ and $M_{n, n \beta}$ represent the transformation matrices from $S_{p}$ to $S_{c}$, $S_{p \gamma}$ to $S_{p}, S_{n}$ to $S_{p \gamma}$ and $S_{n \beta}$ to $S_{n}$, respectively.

Then, the position coordinates and unit normal vectors for the cutter in $S_{c}$ can be expressed as follows

(1) The straight line segment $M_{0}^{r(l)} M_{1}^{r(l)}$ in coordinate system $S_{c}$ 


$$
\begin{aligned}
& \left\{\begin{aligned}
x_{c}= & -\cos (\gamma+\Delta \gamma)\left(a+c_{n} m_{n}\right) \mp \sin (\gamma+\Delta \gamma) \sin (\beta+\Delta \beta)\left(e-e_{f}-\rho \cos \alpha_{n}-q-a \tan \alpha_{n}\right) \\
& +u \sin (\gamma+\Delta \gamma) \cos (\beta+\Delta \beta) \\
y_{c}= & \pm \cos (\beta+\Delta \beta)\left(e-e_{f}-\rho \cos \alpha_{n}-q-a \tan \alpha_{n}\right)+u \sin (\beta+\Delta \beta) \\
z_{c}= & \sin (\gamma+\Delta \gamma)\left(a+c_{n} m_{n}\right) \mp \cos (\gamma+\Delta \gamma) \sin (\beta+\Delta \beta)\left(e-e_{f}-\rho \cos \alpha_{n}-q-a \tan \alpha_{n}\right) \\
& +u \cos (\gamma+\Delta \gamma) \cos (\beta+\Delta \beta)
\end{aligned}\right. \\
& \begin{cases}n_{x c}=\mp \cos (\gamma+\Delta \gamma) \\
n_{y c}=0 \\
n_{z c}= \pm \sin (\gamma+\Delta \gamma)\end{cases}
\end{aligned}
$$

(2) The arc segment $M_{1}^{r(l)} M_{2}^{r(l)}$ in coordinate system $S_{c}$

$$
\begin{aligned}
& \left\{\begin{aligned}
& x_{c}=\mp \sin (\gamma+\Delta \gamma) \sin (\beta+\Delta \beta)\left(\rho \sin \theta-\rho \cos \alpha_{n}-q-a \tan \alpha_{n}\right)+u \sin (\gamma+\Delta \gamma) \cos (\beta+\Delta \beta)+\cos (\gamma+\Delta \gamma)\left(-\rho \cos \theta+\rho \sin \alpha_{n}-a\right) \\
& y_{c}= \pm \cos (\beta+\Delta \beta)\left(\rho \sin \theta-\rho \cos \alpha_{n}-q-a \tan \alpha_{n}\right)+u \sin (\beta+\Delta \beta) \\
& z_{c}=\mp \cos (\gamma+\Delta \gamma) \sin (\beta+\Delta \beta)\left(\rho \sin \theta-\rho \cos \alpha_{n}-q-a \tan \alpha_{n}\right) \\
& \quad+u \cos (\gamma+\Delta \gamma) \cos (\beta+\Delta \beta)-\sin (\gamma+\Delta \gamma)\left(-\rho \cos \theta+\rho \sin \alpha_{n}-a\right)
\end{aligned}\right. \\
& \begin{cases}n_{x c}=-\sin (\beta+\Delta \beta) \sin (\gamma+\Delta \gamma) \sin \theta \mp \cos (\gamma+\Delta \gamma) \cos \theta \\
n_{y c}=\cos (\beta+\Delta \beta) \sin \theta \\
n_{z c}=-\sin (\beta+\Delta \beta) \cos (\gamma+\Delta \gamma) \sin \theta \pm \sin (\gamma+\Delta \gamma) \cos \theta\end{cases}
\end{aligned}
$$

(3) The straight line segment $M_{2}^{r(l)} M_{3}^{r(l)}$ in coordinate system $S_{c}$

$$
\begin{aligned}
& \left\{\begin{aligned}
x_{c}= & \cos (\gamma+\Delta \gamma)\left(l \cos \alpha_{n}-a\right) \mp \sin (\gamma+\Delta \gamma) \sin (\beta+\Delta \beta)\left(l \sin \alpha_{n}-q-a \tan \alpha_{n}\right) \\
& +u \sin (\gamma+\Delta \gamma) \cos (\beta+\Delta \beta) \\
y_{c}= & \pm \cos (\beta+\Delta \beta)\left(l \cos \alpha_{n}-a\right)+u \sin (\beta+\Delta \beta) \\
z_{c}= & -\sin (\gamma+\Delta \gamma)\left(l \cos \alpha_{n}-a\right) \mp \cos (\gamma+\Delta \gamma) \sin (\beta+\Delta \beta)\left(l \sin \alpha_{n}-q-a \tan \alpha_{n}\right) \\
& +u \cos (\gamma+\Delta \gamma) \cos (\beta+\Delta \beta)
\end{aligned}\right. \\
& \begin{cases}n_{x c}=-\cos \alpha_{n} \sin (\beta+\Delta \beta) \sin (\gamma+\Delta \gamma) \mp \cos (\gamma+\Delta \gamma) \sin \alpha_{n} \\
n_{y c}=\cos (\beta+\Delta \beta) \cos \alpha_{n} \\
n_{z c}=-\cos \alpha_{n} \sin (\beta+\Delta \beta) \cos (\gamma+\Delta \gamma) \pm \sin (\gamma+\Delta \gamma) \sin \alpha_{n}\end{cases}
\end{aligned}
$$

Where the upper sign and lower sign denote the left and right sides of the cutter, respectively. $x, y$ and $z$ denote the position coordinates. $n_{x}, n_{y}, n_{z}$ denote the unit normal vectors. $\theta$ denotes the parameter for the fillet segment with its range between 0 and $\left(90^{\circ}-\alpha_{n}\right) . l$ denotes the distance from $M_{2}^{r(l)}$ to the point located on $M_{2}^{r(l)} M_{3}^{r(l)}$ and the length of the line is $\overline{M_{2}^{r(l)} M_{3}^{r(l)}}=2 m_{n} / \cos \alpha_{n}$.e denotes the distance from $M_{0}^{r(l)}$ to the point located on $M_{0}^{r(l)} M_{1}^{r(l)}$. It varies from 0 to $e_{f}$. For the maximum value $e_{f}$, it can be calculated by

$$
e_{f}=P_{c} / 4-m_{n} \tan \alpha_{n}-c_{n} m_{n} \cos \alpha_{n} /\left(1-\sin \alpha_{n}\right)
$$

Then, the beveloid tooth surface in $S_{j}$ is

$$
\begin{aligned}
& R_{j}=M_{j, c} R_{c} \\
& M_{j, c}=\left[\begin{array}{cccc}
\cos \varphi_{j} & -\sin \varphi_{j} & 0 & r_{j} \cos \varphi_{j}+r_{j} \varphi_{j} \sin \varphi_{j} \\
\sin \varphi_{j} & \cos \varphi_{j} & 0 & r_{j} \sin \varphi_{j}-r_{j} \varphi_{j} \cos \varphi_{j} \\
0 & 0 & 1 & 0 \\
0 & 0 & 0 & 1
\end{array}\right]
\end{aligned}
$$

Where $R_{j}$ denotes the position vector and $M_{j, c}$ denotes the transformation matrices from $S_{c}$ to $S_{j}$.

Hence the beveloid gear model considering machine tool adjustment errors in coordinate $S_{j}$ can be obtained by 


$$
\left\{\begin{array}{l}
x_{j}=x_{c} \cos \varphi_{j}-y_{c} \sin \varphi_{j}+r_{j} \cos \varphi_{j}+r_{j} \varphi_{j} \sin \varphi_{j} \\
y_{j}=x_{c} \sin \varphi_{j}+y_{c} \cos \varphi_{j}+r_{j} \sin \varphi_{j}-r_{j} \varphi_{j} \cos \varphi_{j} \\
z_{j}=z_{c}
\end{array}\right.
$$

Where the meshing equation is

$$
\varphi_{j}=\left(n_{x c} y_{c}-n_{y c} x_{c}\right) /\left(n_{x c} r_{j}\right)
$$

Based on the proposed model, three groups of machine tool adjustment errors are selected as listed in Table 1. Then the coding work by Matlab was performed to calculated and plot the beveloid gear tooth surface with machine tool adjustment errors as shown in Fig.4.

\begin{tabular}{|c|c|c|c|c|c|c|c|c|c|c|c|c|c|}
\hline Number of teeth $N$ & \multicolumn{13}{|c|}{20} \\
\hline Tooth width $b(\mathrm{~mm})$ & \multicolumn{13}{|c|}{18} \\
\hline $\begin{array}{c}\text { Normal module } \\
m_{n}(\mathrm{~mm})\end{array}$ & \multicolumn{13}{|c|}{3} \\
\hline Cone angle $\gamma\left({ }^{\circ}\right)$ & \multicolumn{13}{|c|}{6} \\
\hline Helix angle $\beta\left(^{\circ}\right)$ & \multicolumn{13}{|c|}{$9(\mathrm{RH})$} \\
\hline $\begin{array}{l}\text { Normal pressure angle } \\
\qquad \alpha_{n}\left({ }^{\circ}\right) \\
\end{array}$ & \multicolumn{13}{|c|}{20} \\
\hline \multirow[t]{2}{*}{ Profile shifting factor $x_{t}$} & \multicolumn{13}{|c|}{0.0100 (Toe) } \\
\hline & \multicolumn{5}{|c|}{ Independent helix angle error } & \multicolumn{4}{|c|}{$\begin{array}{c}\text { Independent cone angle } \\
\text { error }\end{array}$} & \multicolumn{4}{|c|}{ Combined angle error } \\
\hline $\begin{array}{l}\text { Helix angle error } \\
\qquad \Delta \beta\left(^{\circ}\right)\end{array}$ & 0 & -0.2 & -0.1 & 0.1 & 0.2 & 0 & 0 & 0 & 0 & -0.2 & -0.1 & 0.1 & 0.2 \\
\hline $\begin{array}{c}\text { Cone angle error } \\
\Delta \gamma\left(\left(^{\circ}\right)\right.\end{array}$ & 0 & 0 & 0 & 0 & 0 & -0.2 & -0.1 & 0.1 & 0.2 & -0.2 & -0.1 & 0.1 & 0.2 \\
\hline
\end{tabular}

Table 1 Geometry parameters with machine tool adjustment errors

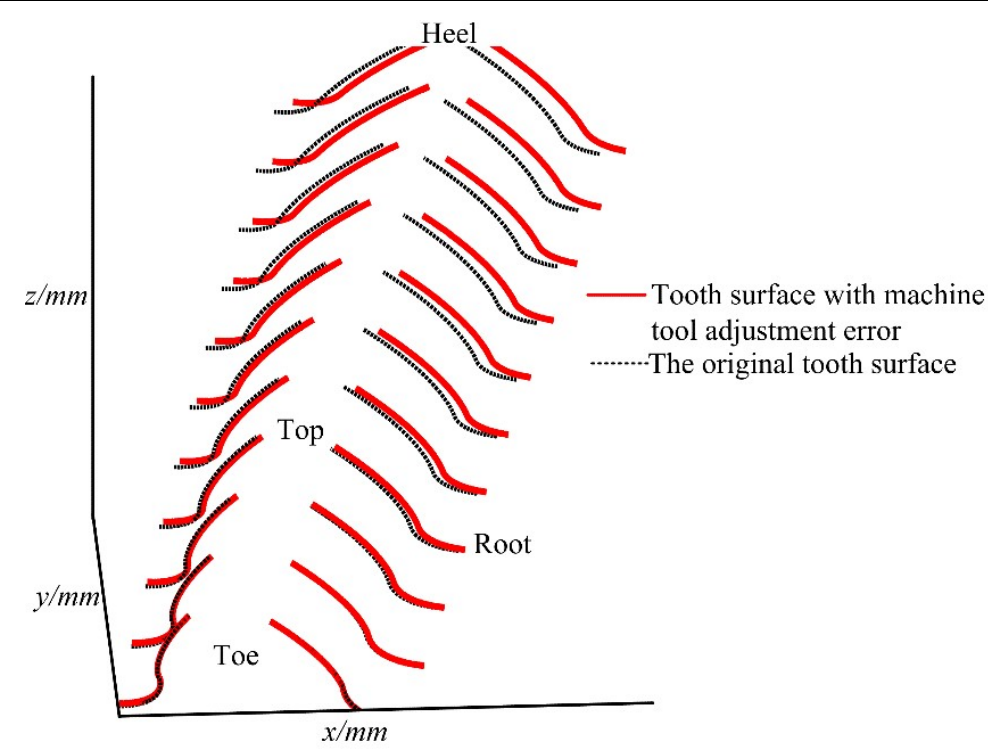

Fig. 4 Beveloid gear tooth surface with machine tool adjustment errors

\section{Deviation analysis of a beveloid gear}

\subsection{Definitions of tooth profile and tooth trace deviations for beveloid gear}

For the conventional cylindrical gear, the tooth profile deviation $\Delta f_{t}$ is defined as the minimum normal distance between the design tooth profile and the real tooth profile on the working flank. The tooth trace deviation $f_{f \beta}$ is defined as the minimum distance between the design tooth trace and the real tooth trace on the reference cylinder as shown in Fig.5. 


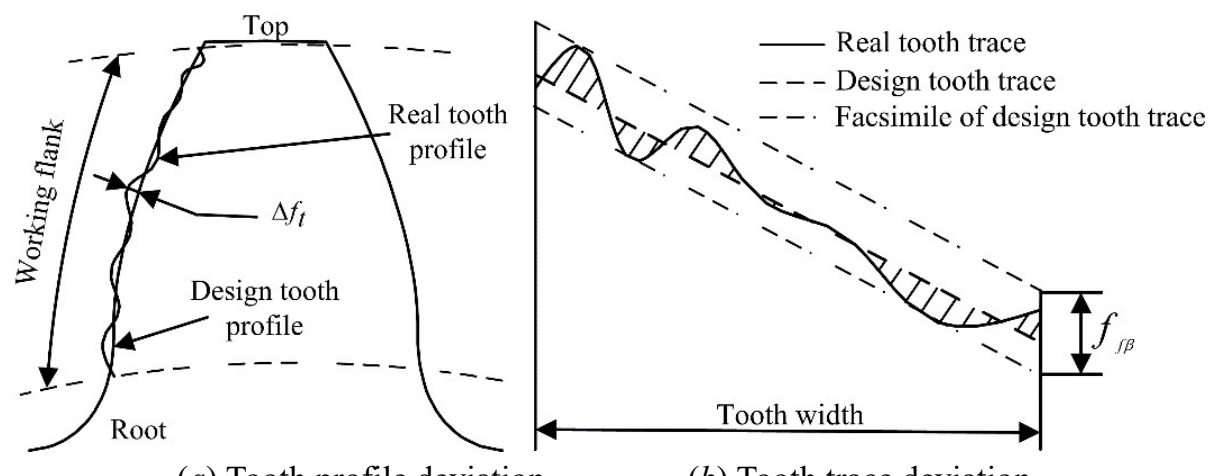

(a) Tooth profile deviation

(b) Tooth trace deviation

Fig.5 The tooth profile and trace deviations for cylindrical gear

Since the beveloid gear can be considered as the superposition of numerous slices of conventional cylindrical involute gears with different profile shifting factors, the profile deviation of beveloid gear in each cross section can be calculated separately. Also, the design of beveloid gear is based on the working pitch cone theory and the working pitch circle is not coincident to the reference circle during meshing. As shown in Fig.6, the tooth trace of beveloid gear is defined as the intersecting line of the working tooth flank and the working pitch cone. Therefore, the tooth trace deviation of beveloid can be presented by the minimum distance between the design and the real tooth traces.

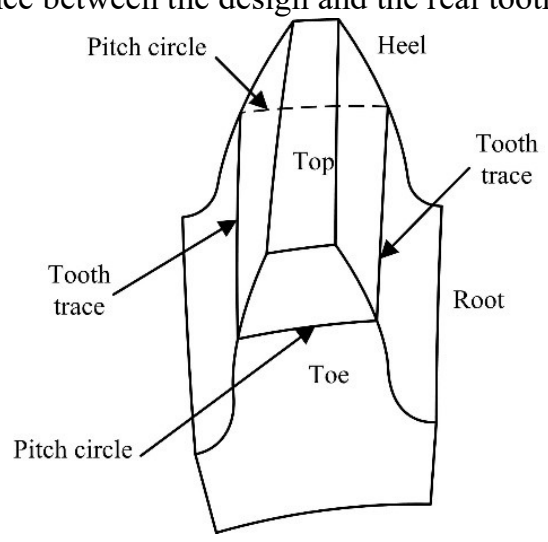

Fig.6 Definition for the beveloid tooth trace

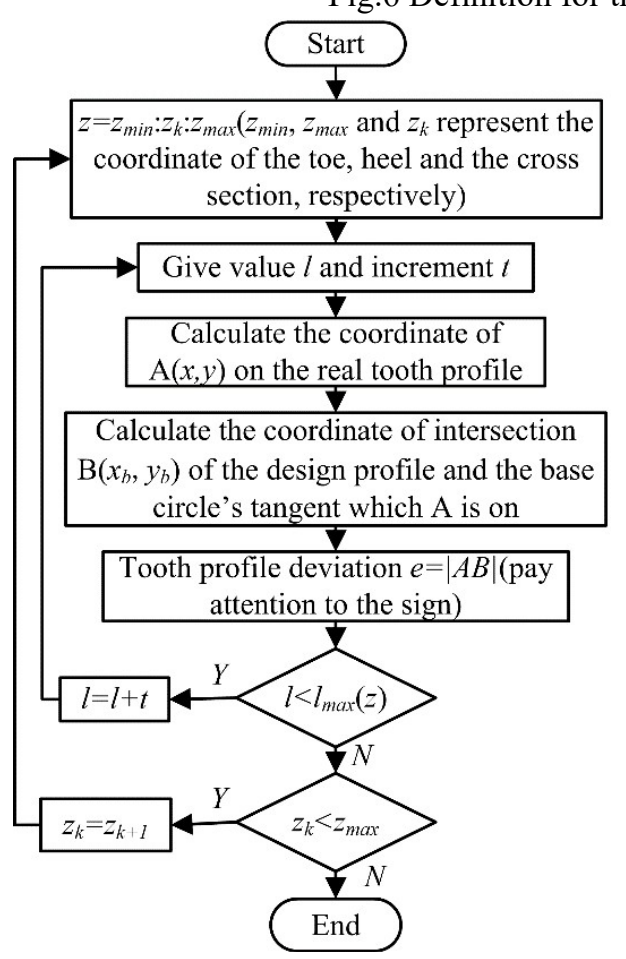

(a) Tooth profile deviation

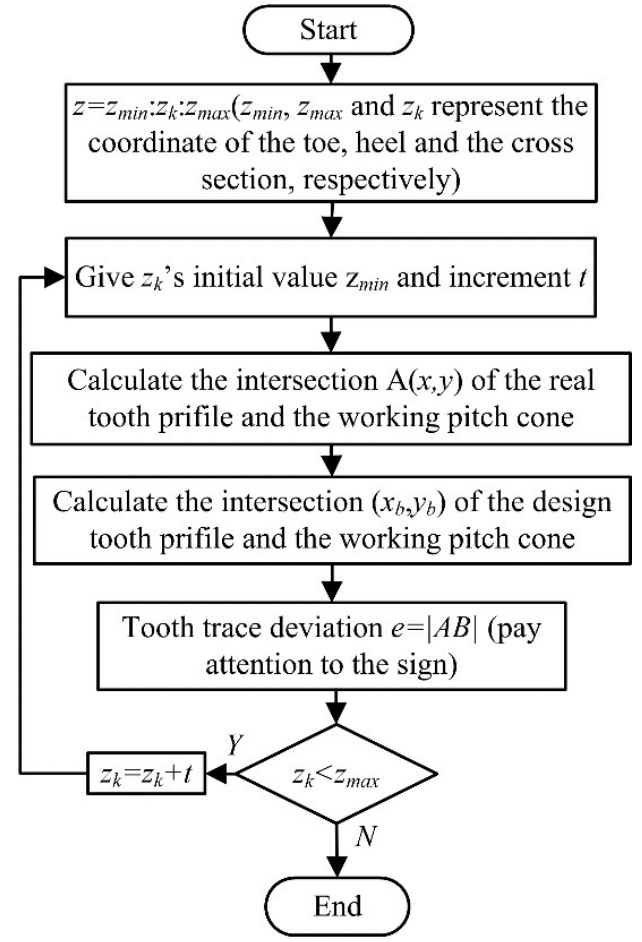

(b) Tooth trace deviation

Fig.7 Flow chart for tooth surface deviations calculation 
The flow chart for the calculation of tooth profile and tooth trace deviations are summarized as shown in Fig.7. In the figure, $z$ represents the coordinate of the cross section of the gear, $l$ is the important parameter when manufacturing mentioned in Chapter 2, $t$ is the increment of $l, \mathrm{~A}(x, y)$ represents the coordinate of the point on the real tooth profile when the $z$ and $l$ are given, B $\left(x_{b}, y_{b}\right)$ represents the coordinate of the point on the design tooth profile when the point A is given. For the sign convention of the deviation, it is positive if the real tooth profile is located on the right side of the design tooth profile when observing from the toe to the heel, otherwise the deviation is negative.

\subsection{Influence of independent helix angle error on tooth surface deviations}

The comparison for beveloid gear tooth surfaces with and without helix angle error is shown in Fig.8. From the figure, the tooth surface in the heel changes a lot. However, the helix angle error does not affect the tooth surface in the toe obviously as well as the tooth root part. Designing the left tooth surface as the working tooth surface when observing from toe to heel, the effects of helix angle error on tooth profile deviation for different sections along the tooth trace direction are shown in Fig. $9(a) \sim(c)$. The tooth trace deviation results are shown in Fig. $9(d)$.

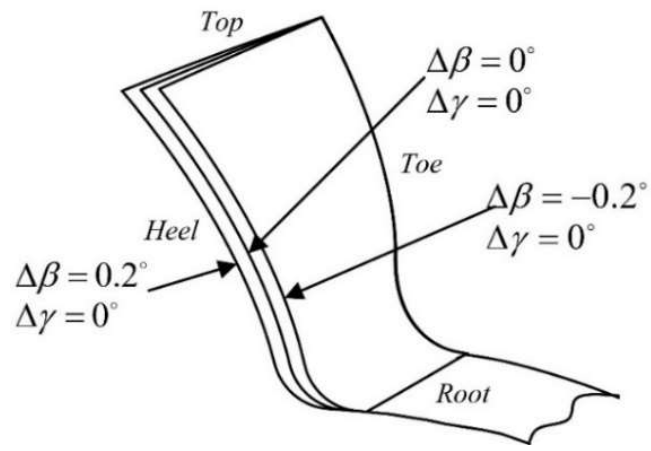

Fig.8 Comparison for beveloid gear tooth surfaces with and without helix angle error

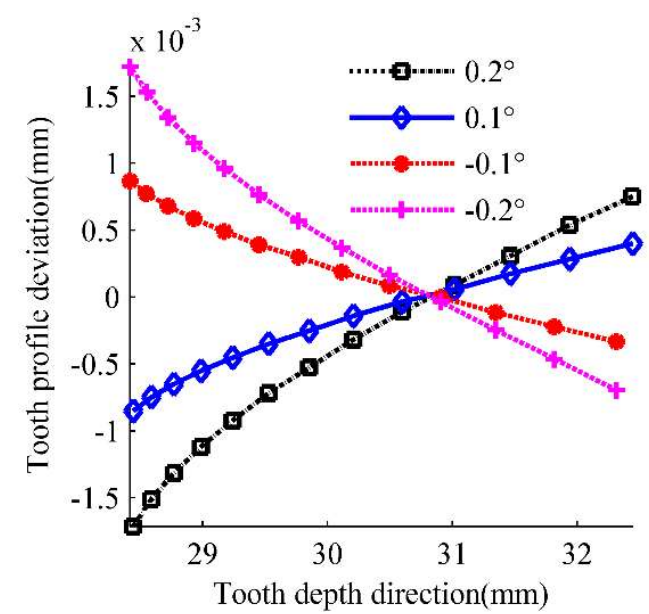

(a) Tooth profile deviation in the toe

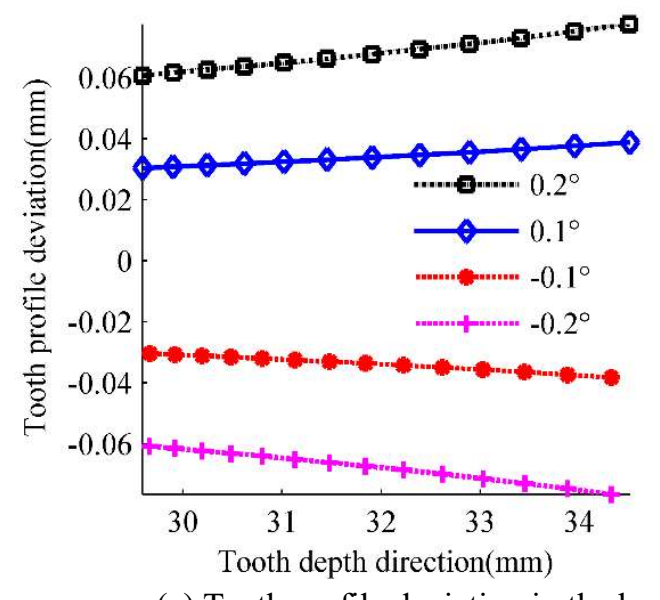

(c) Tooth profile deviation in the heel

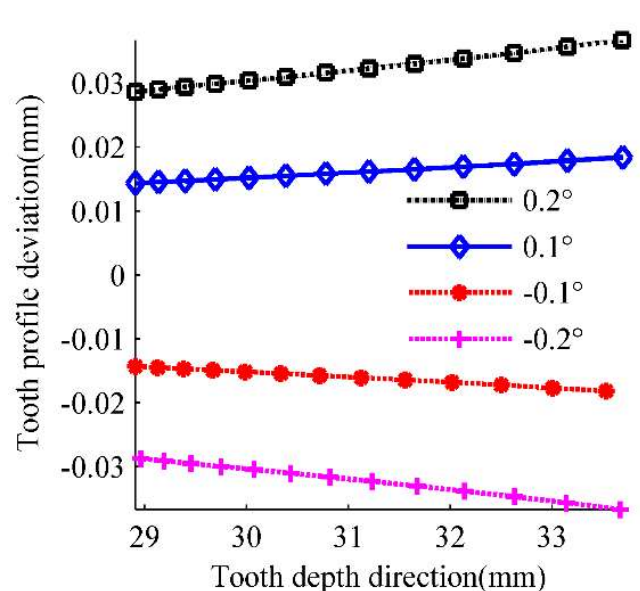

(b) Tooth profile deviation in the midsection

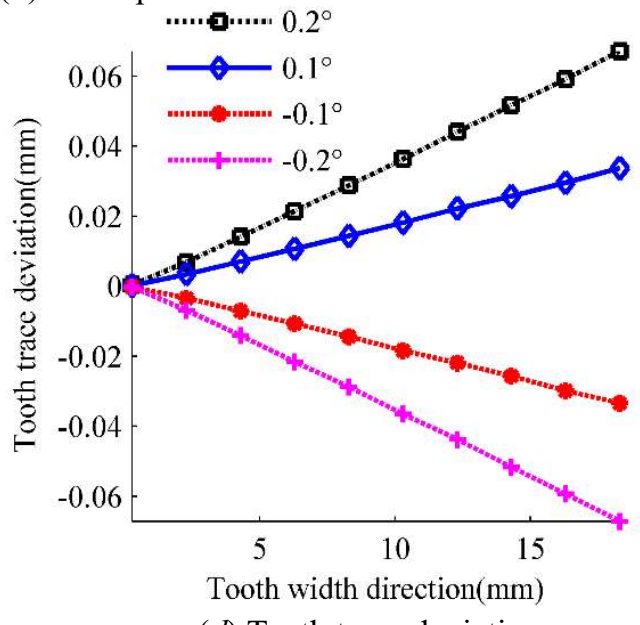

(d) Tooth trace deviation 
Fig.9 Effects of helix angle error on tooth surface deviations

From the results, both the tooth profile and trace deviations change symmetrically with the variation of helix angle error from $-0.2^{\circ}$ to $0.2^{\circ}$. In the toe, the tooth profile deviations decrease firstly and then increase from the root to the top. However, the maximum deviation is only about $0.0015 \mathrm{~mm}$ at the root. For both the midsection and heel, the increase of the helix angle error increases the tooth profile deviation and the deviation magnitude increases linearly from the root to the top. The maximum tooth profile deviations are about $0.04 \mathrm{~mm}$ and $0.07 \mathrm{~mm}$. The existing of the helix angle error increases the tooth trace deviation linearly from toe to heel. And the maximum deviation is more than $0.06 \mathrm{~mm}$ when the helix angle error is $\pm 0.2^{\circ}$. Also, the tooth profile and tooth trace deviations have the same magnitude level as the tooth surface modification, therefore the helix angle error should have a considerable effect on the mesh characteristics of beveloid gear.

\subsection{Influence of independent cone angle error on tooth surface deviations}

The comparison for beveloid gear tooth surfaces with and without cone angle error is shown in Fig.10. The effect of the cone angle error on the tooth surface in the toe is unsubstantial. However, the cone angle error affects the tooth surface in the heel and the tooth root parts obviously.

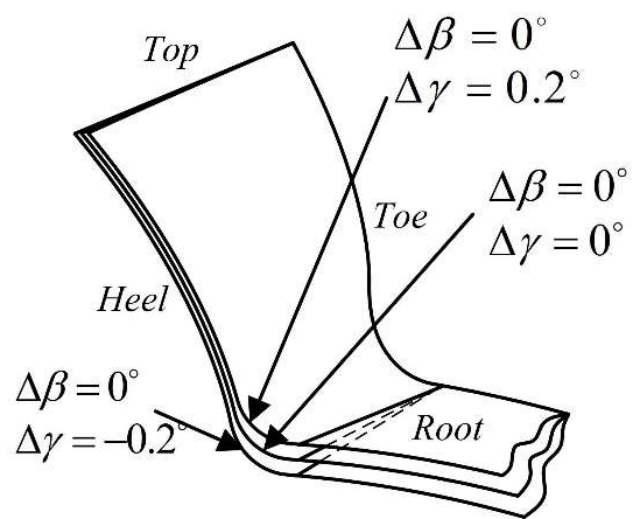

Fig.10 Comparison for beveloid gear tooth surfaces with and without cone angle error

The effects of cone angle error on tooth profile deviation are shown in Fig. $11(a) \sim(c)$. The tooth trace deviation results are shown in Fig.11 $(d)$. Similar to the helix angle error, the tooth profile deviation in the toe decreases firstly and then increases and the maximum profile deviation located in the root is about $0.0012 \mathrm{~mm}$. In the midsection and the heel, the profile deviation increases slowly in the tooth depth direction. Especially for the midsection, the profile deviation almost keeps as a constant. The maximum magnitudes for the two cross sections locate in the top and reach about $0.012 \mathrm{~mm}$ and $0.025 \mathrm{~mm}$. The tooth trace deviation increases linearly from the toe to heel along the tooth width direction, and the maximum deviation is about $0.025 \mathrm{~mm}$ when the magnitude of cone angle is $\pm 0.2^{\circ}$. Also, the cone angle error should have a considerable effect on the mesh characteristics of beveloid gear due to the same magnitude levels for the resulted tooth profile and trace deviations with tooth modifications.
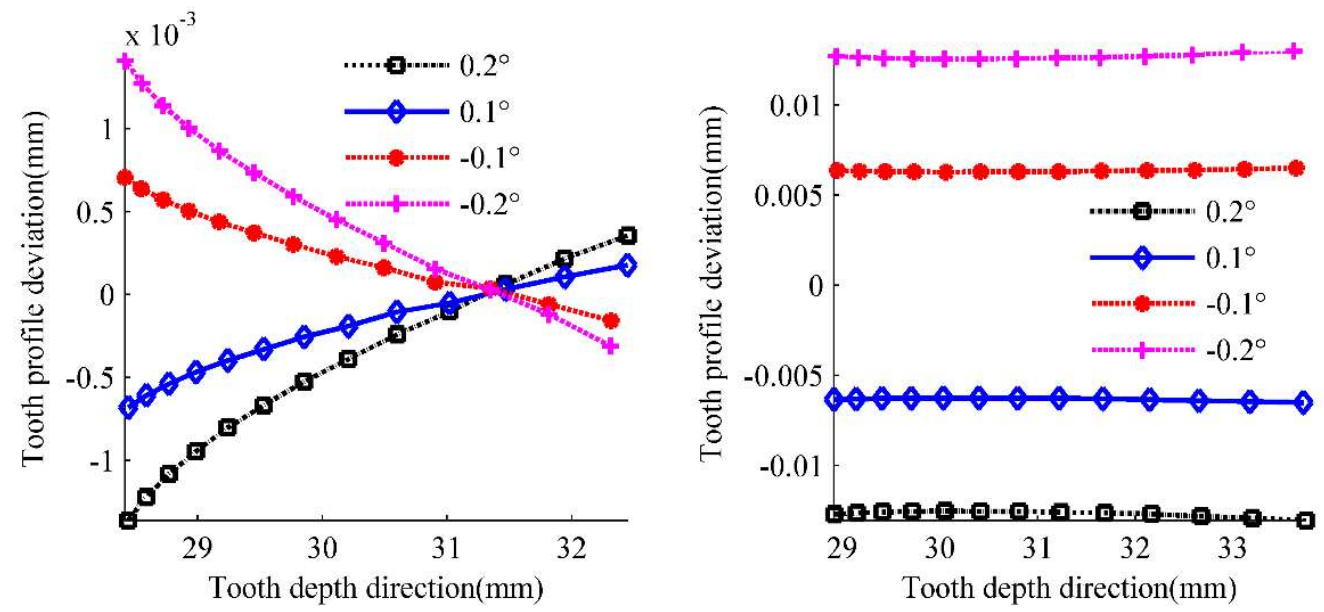

(a) Tooth profile deviation in the toe $(b)$ Tooth profile deviation in the midsection 


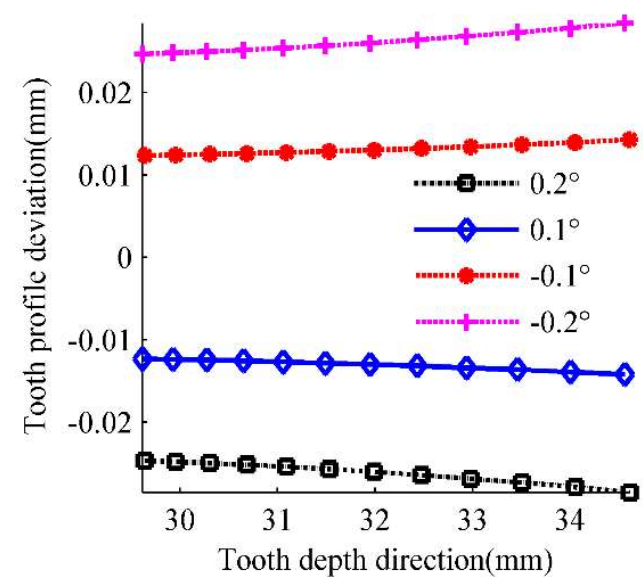

(c) Tooth profile deviation in the heel

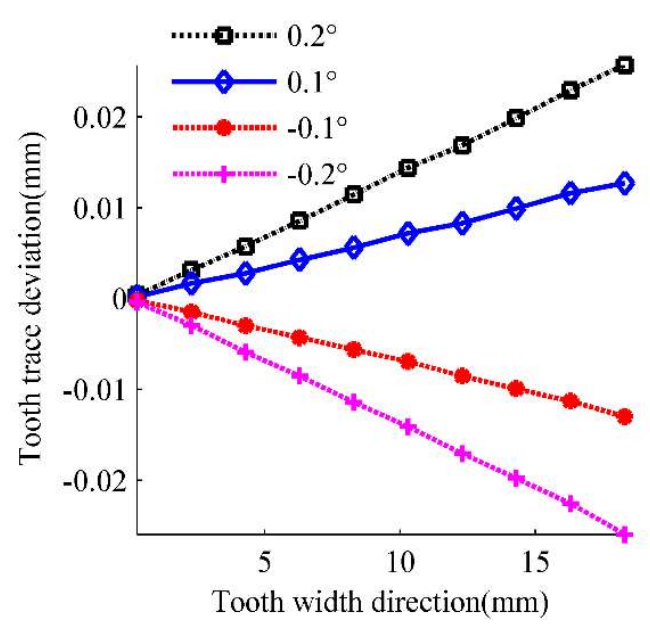

(d) Tooth trace deviation

Fig.11 Effects of cone angle error on tooth surface deviations

\subsection{Influence of the combined helix and cone angle error on tooth surface deviations}

The comparison for the tooth surfaces with and without combined helix and cone angle errors is shown in Fig. 12. Similarly, the tooth surface in the toe change unsubstantially, but the tooth surface in the heel and root parts changes obviously due to the existing of the combined helix and cone angle errors. The effects of combined helix and cone angle errors on the tooth surface deviations for beveloid gear are shown in Fig.13.

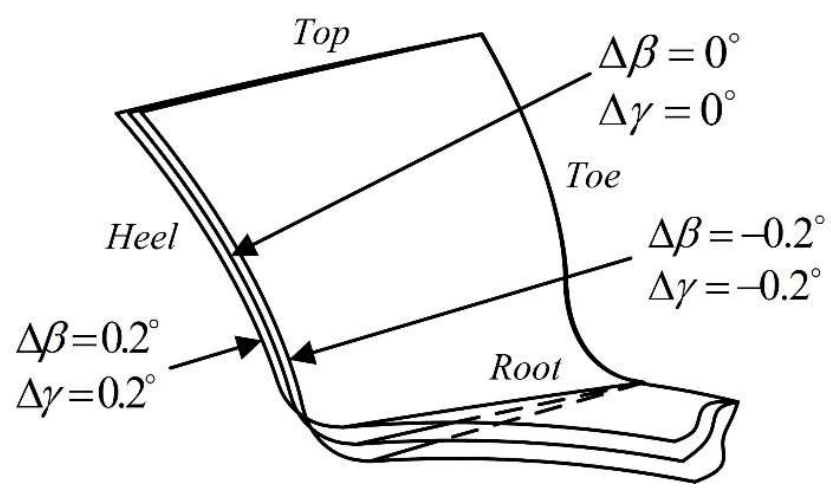

Fig.12 Comparison for tooth surfaces with and without combined errors
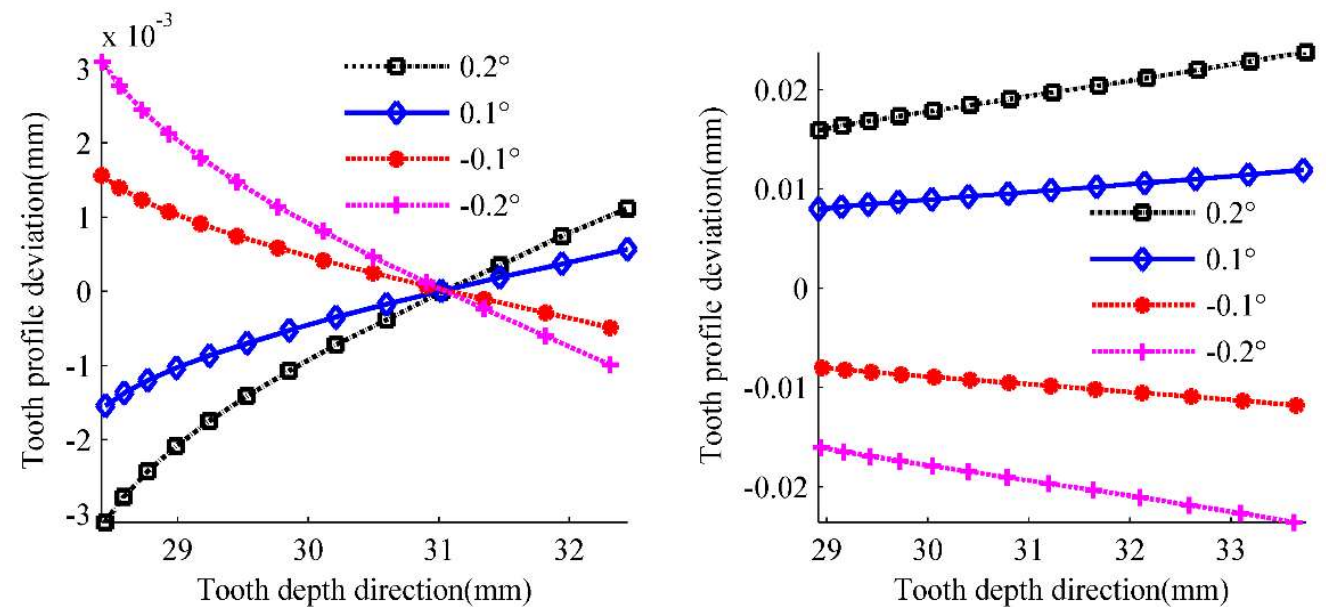

(a) Tooth profile deviation in the toe $(b)$ Tooth profile deviation in the midsection 


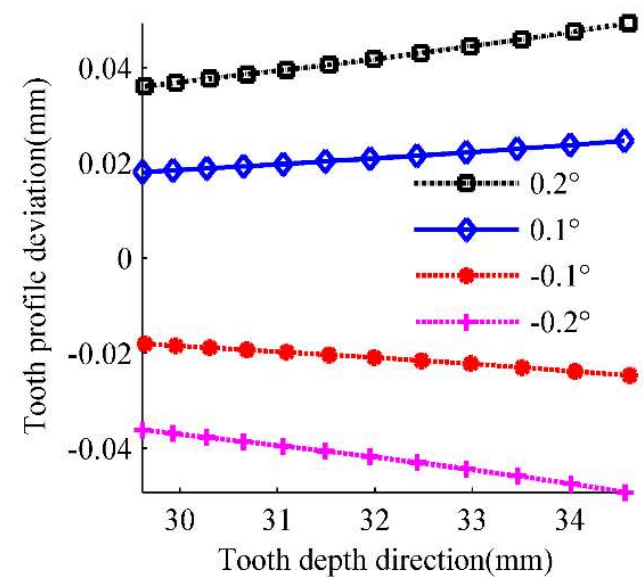

(c) Tooth profile deviation in the heel

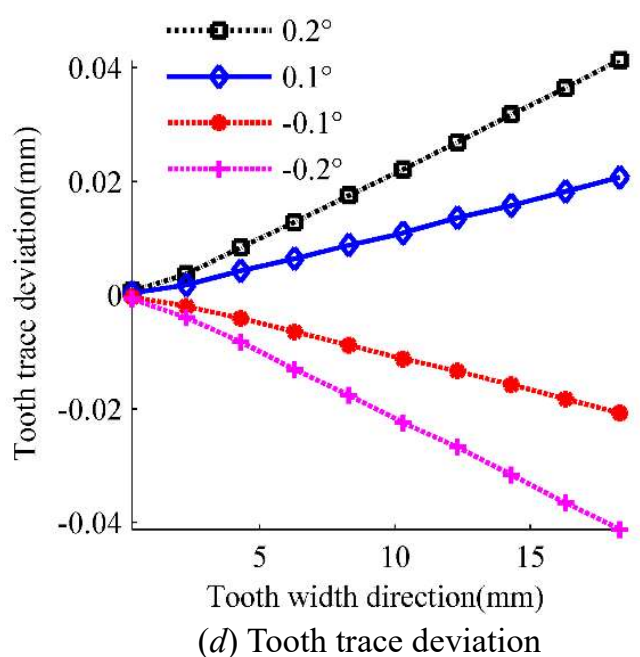

(d) Tooth trace deviation

Fig.13 Effects of the combined errors on tooth surface deviations

Results show that the variation trend for the tooth surface deviations with combined angle errors is similar to that with helix angle error. The maximum tooth profile deviation in the toe located in the root reaches $0.003 \mathrm{~mm}$. For the midsection and the heel, the maximum tooth profile deviations are $0.021 \mathrm{~mm}$ and $0.045 \mathrm{~mm}$, respectively. The maximum tooth trace deviation is about $0.04 \mathrm{~mm}$ when the combined helix and cone angle errors reach $\pm 0.2^{\circ}$.

\section{Mesh characteristics of beveloid gear with parallel axis}

Based on the deviation analysis, the effects of machine tool adjustment errors on the contact characteristics will be investigated subsequently. The main design parameters and torque load for the beveloid gear pair with parallel axis are shown in Table 2. In this paper, only the pinion has machine tool adjustment error and the gear has no errors. The machine adjustment errors are given in Table 1. After obtaining the coordinates of the tooth surface, the solid model of beveloid gear pair considering machine tool adjustment errors can be developed in the CAD software as shown in Fig. 14. Then the commercial finite element software Abaqus is used to develop the mesh model as shown in Fig. 15.

Table 2 Main design parameters and torque load

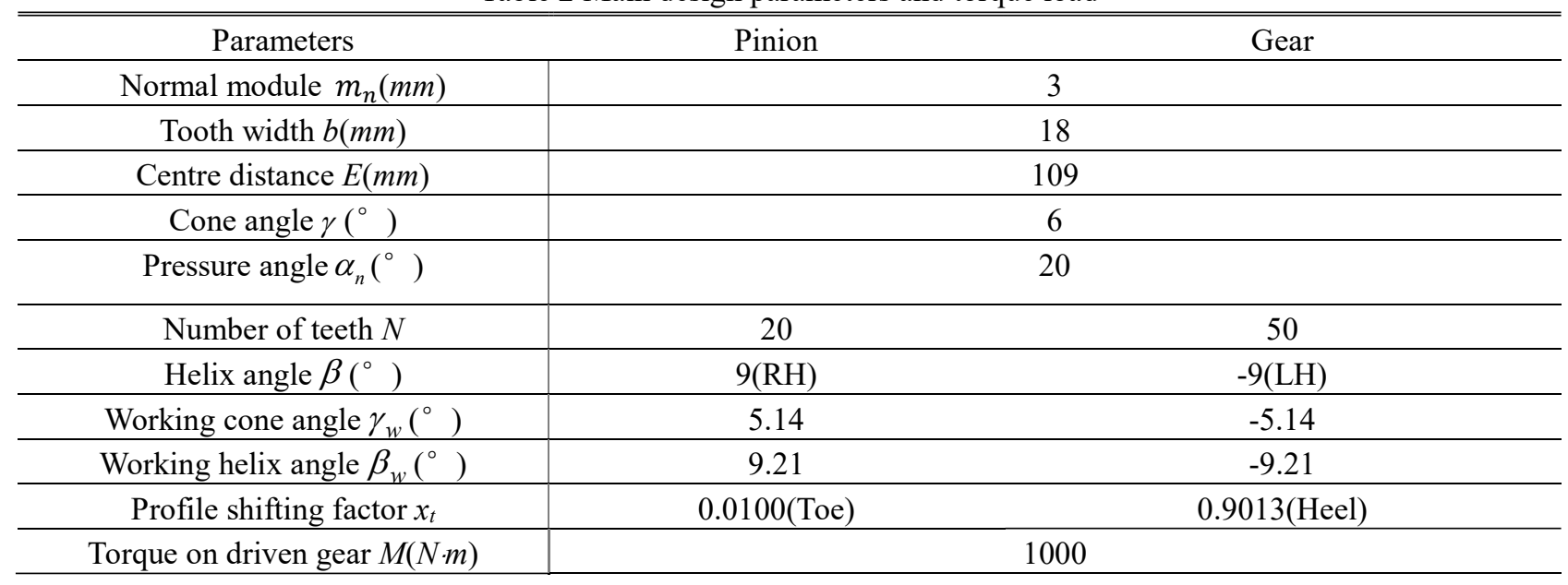

The material of the beveloid gears is defined as 17CrNiMo6 with the Young's modulus 208 GPa and the Poisson's ratio 0.298 . For the simulation, the pinion was defined as the driving gear and the direction of rotation is anticlockwise when observing from the toe to the heel. 


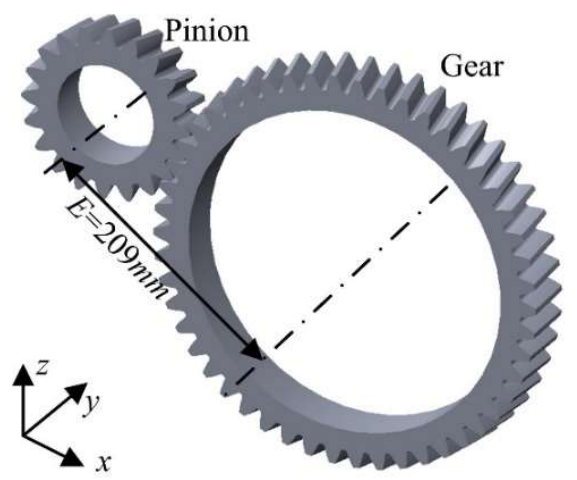

Fig.14 Solid assembly model

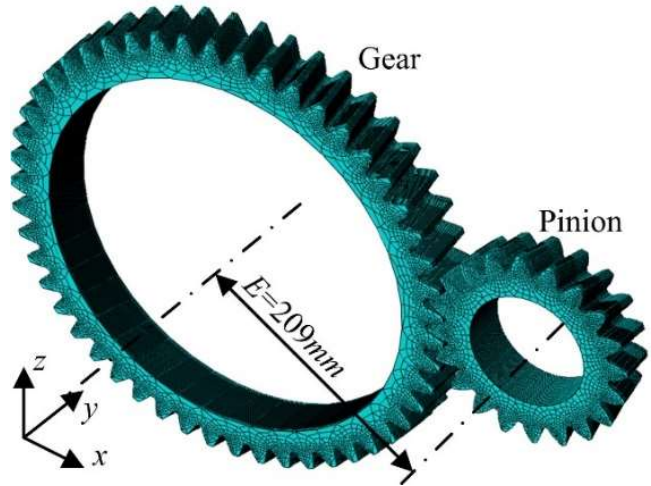

Fig. 15 Finite element mesh model

\subsection{Influence of independent helix angle error on contact characteristics}

The contact pattern results for pinion and angular transmission error results with independent helix angle error are illustrated in Fig.16 and Fig.17. From the results, the positive and negative helix angle errors shift the locations of the contact area to the toe and the heel obviously, respectively. The area of the contact pattern is decreased and the maximum contact pressure is increased obviously due to the helix angle error. The existing of independent helix angle error would cause serious edge contact in the toe or heel. For the angular transmission error, it becomes obviously worse with a much higher peak-to-peak value due to the serious edge contact.

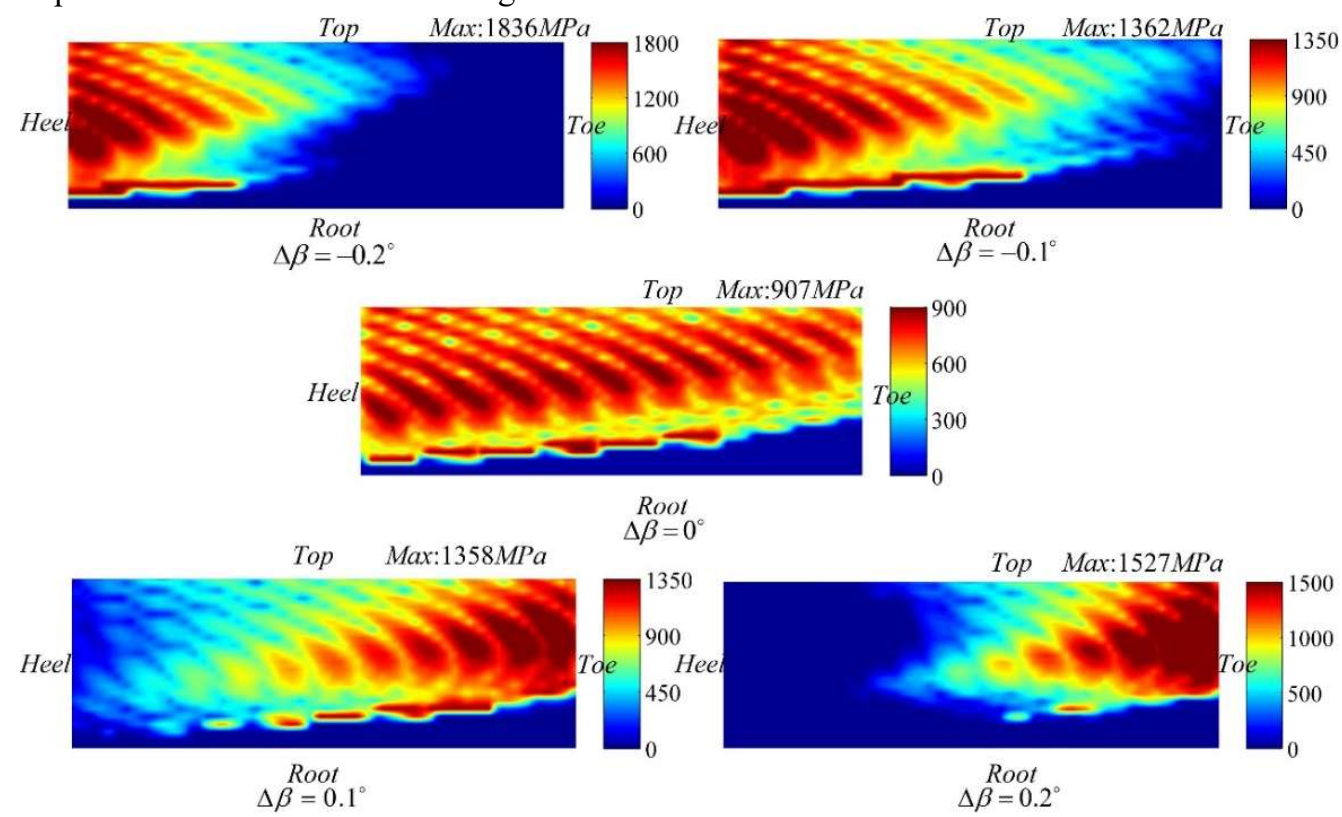

Fig.16 Contact pattern on pinion with independent helix angle error

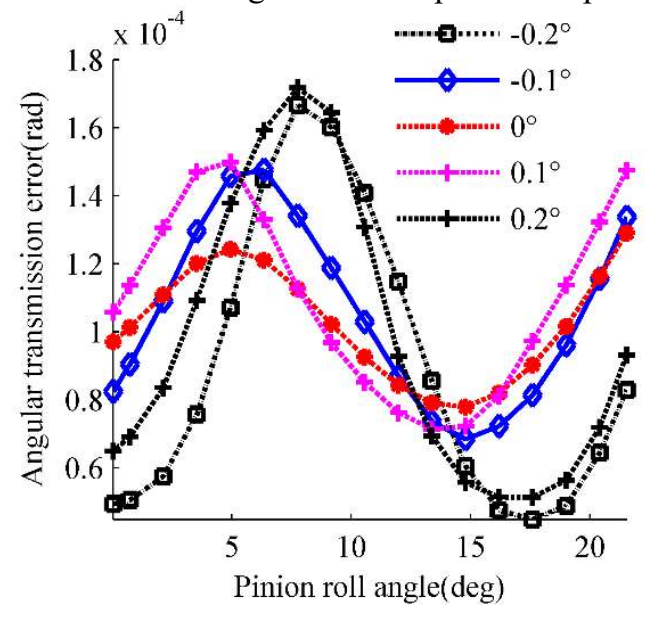

(a) Time-varying value

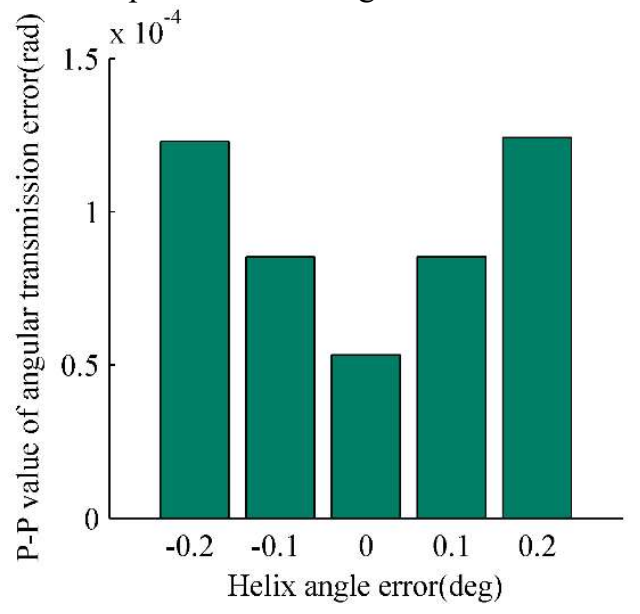

(b) Peak-Peak value

Fig.17 Angular transmission error with independent helix angle error 


\subsection{Influence of independent cone angle error on contact characteristics}

The contact pattern for pinion and angular transmission error results with independent cone angle error are shown in Fig.18 and Fig.19, respectively. Compared to the independent helix angle error, the contact pattern moves in the opposite trend due to the cone angle error. However, for the same magnitude $\pm 0.2^{\circ}$, the impact of the independent cone angle error is not so substantial as the independent helix angle error. And the maximum contact pressure is increased slightly due to the existing of cone angle error. Similar to the independent helix angle error, the independent cone angle error has a worsen effect with a slightly higher peak-to-peak value on the angular transmission error. In brief, the independent cone angle error has less effects both on the contact pattern and transmission error.

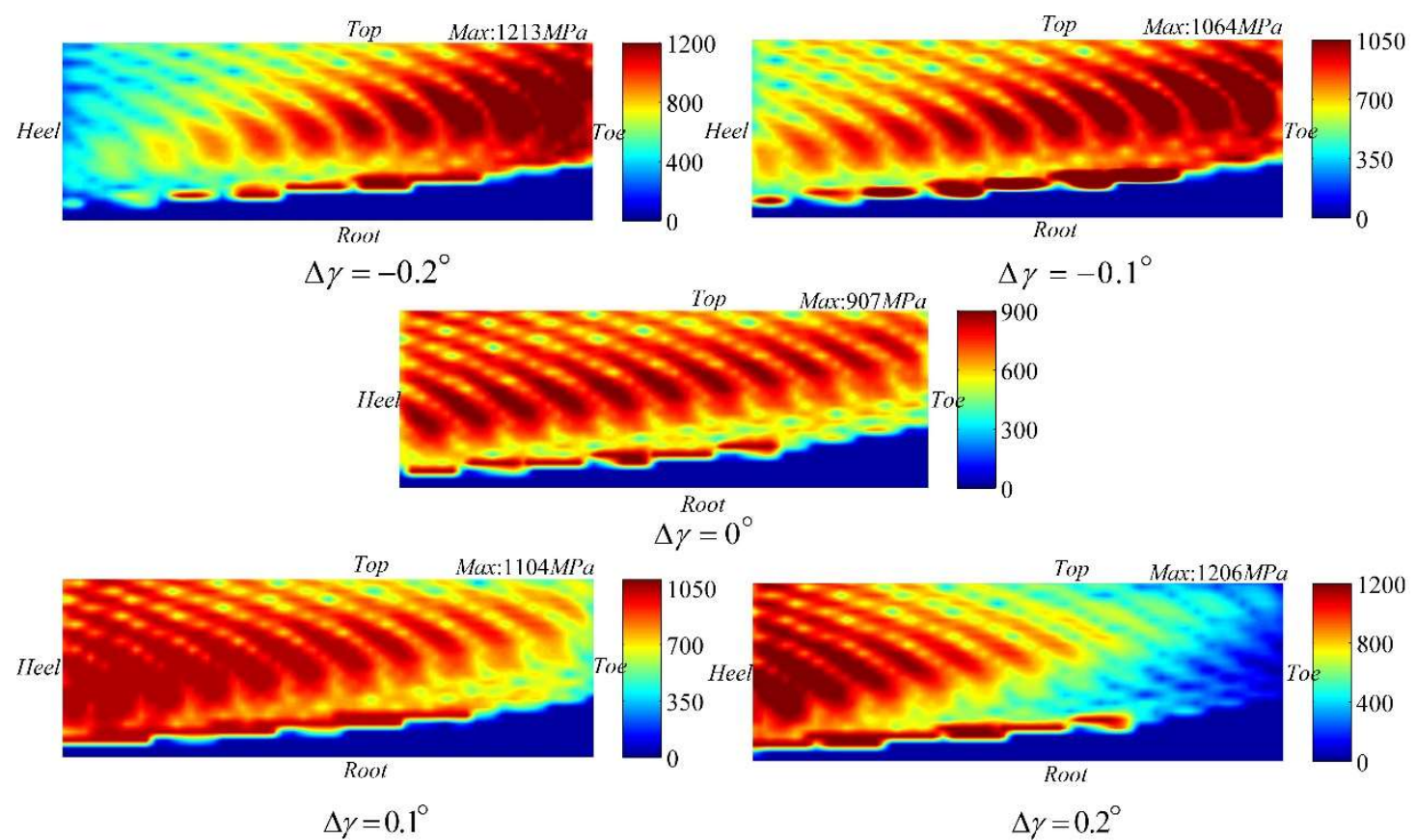

Fig.18 Contact pattern on pinion with independent cone angle error

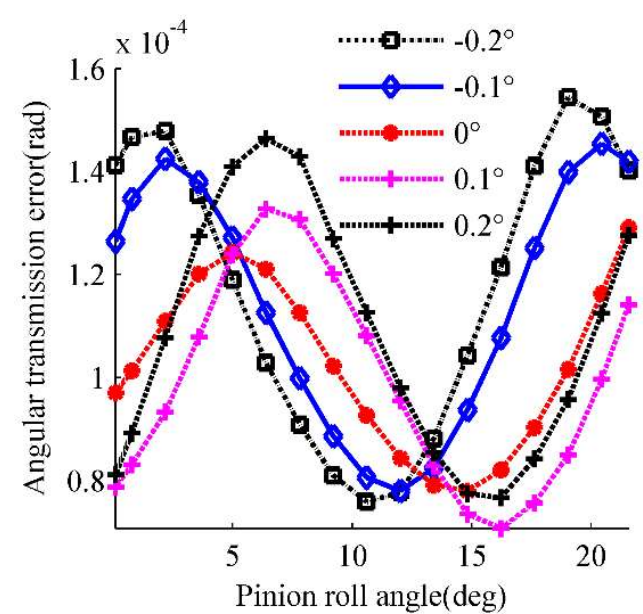

(a) Time-varying value

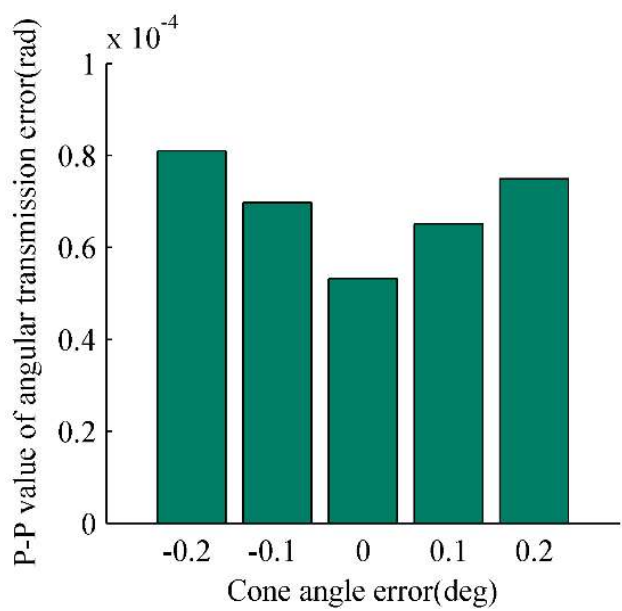

(b) Peak-Peak value

Fig.19 Angular transmission error with independent cone angle error

\subsection{Influence of combined helix and cone angle errors on contact characteristics}

The contact pattern for pinion and angular transmission error results with combined helix and cone angle errors are illustrated in Fig.20 and Fig.21. Similar to the investigation of the effects on the deviations, the combined helix and cone angle errors are designed as five groups including both $-0.2^{\circ},-0.1^{\circ}, 0^{\circ}, 0.1^{\circ}$ and $0.2^{\circ}$ as shown in Tab.1. Similar to the independent helix angle error, the positive and negative combined helix and cone angle errors have the same impact on the shifting direction of the contact pattern. The area of the contact pattern is decreased and the maximum contact pressure is increased obviously due to the existing of combined helix and cone angle errors. For the angular transmission error, 
since the mesh becomes worse as shown in the contact pattern results, it also obviously becomes worsen with a higher peak-to-peak value with the combined helix and cone angle errors.

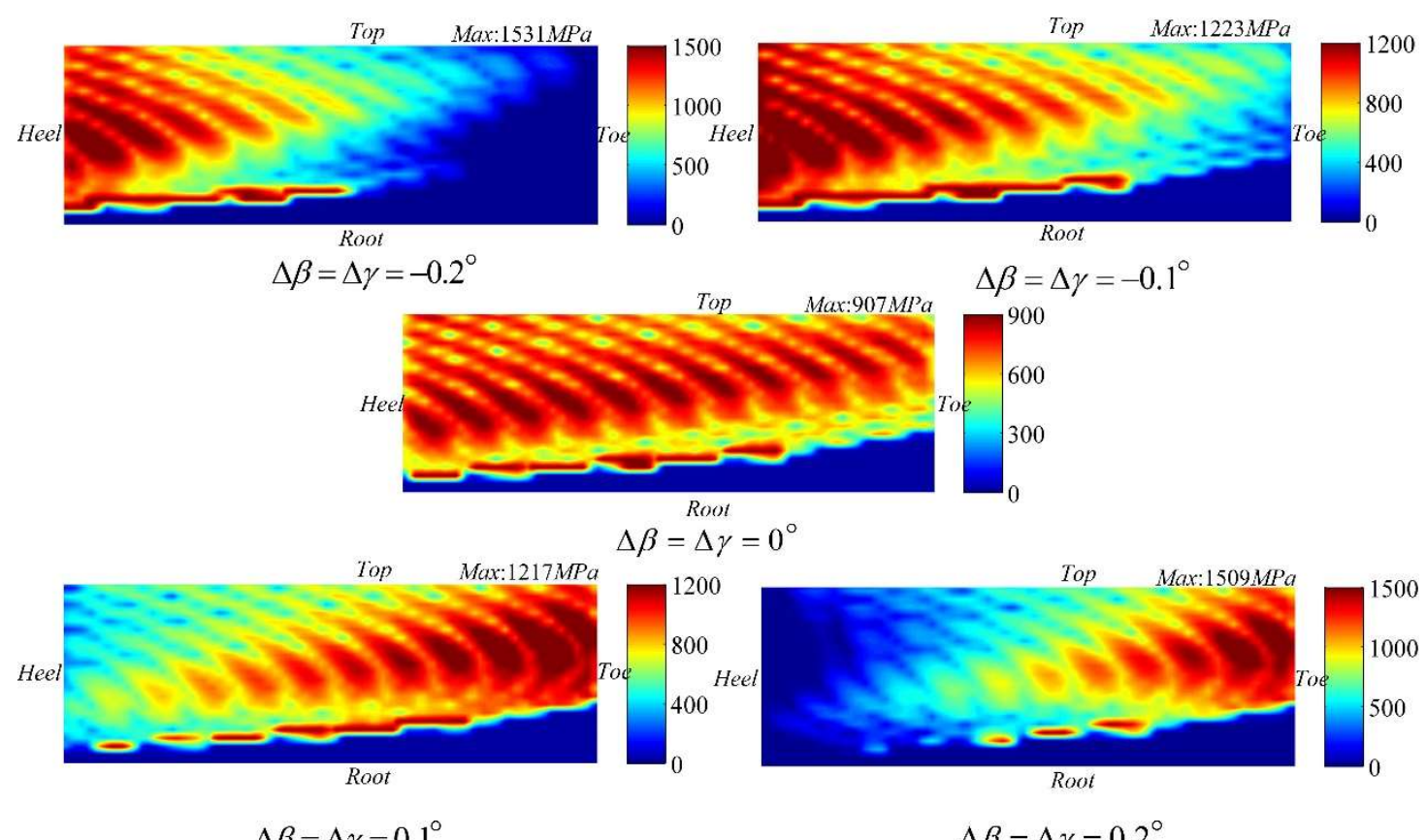

$\Delta \beta=\Delta \gamma=0.1^{\circ}$

$\Delta \beta=\Delta \gamma=0.2^{\circ}$

Fig.20 Contact pattern on pinion with combined angle errors

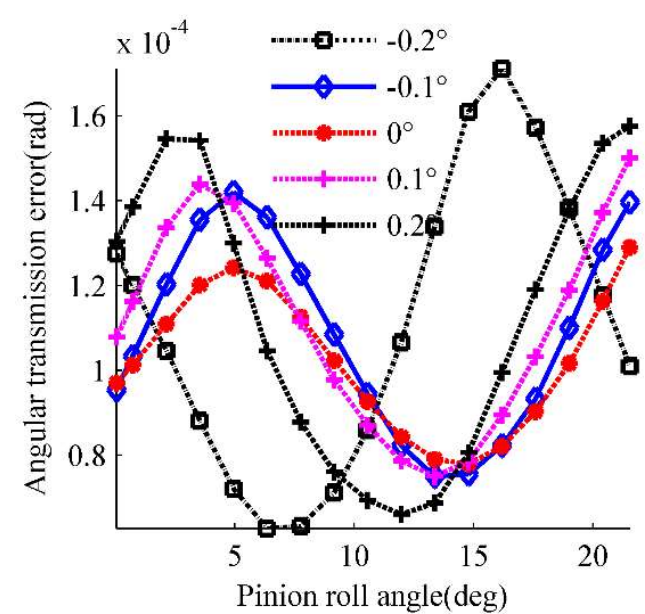

(a) Time-varying value

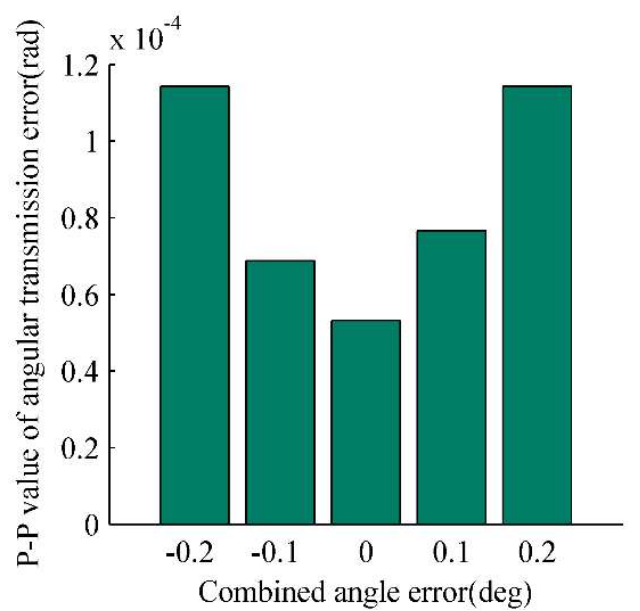

(b) Peak-Peak value

Fig.21 Angular transmission error with combined angle errors

\section{Conclusion}

(1) The mathematical beveloid gear tooth surface model considering machine tool adjustment errors was derived. The definition and calculation process of tooth surface deviations along the tooth trace and profile directions for beveloid gear were proposed. Also, the solid model and the finite element mesh model of a paralleled beveloid gear pair were developed. Then, the effects of the machine tool adjustment errors including independent helix angle error, independent cone angle error and combined helix and cone angle errors on the tooth surface deviation and contact characteristics were investigated.

(2) All the machine tool adjustment errors cause an incremental trend for the tooth profile and tooth trace deviations. And positive errors have the opposite impact on the surface deviation compared with the negative errors. The independent helix angle error has a stronger impact on the tooth surface deviations than the independent cone angle error and combined angle errors. Also, the tooth surface deviations caused by the independent helix angle error, independent cone angle error and combined angle errors have the similar magnitude level as the tooth surface modifications. 
(3) All the independent helix angle error, independent cone angle error and combined angle errors tend to have deteriorative effects on the mesh characteristics, making edge contact worse, decreasing the contact area, increasing the contact pressure and the transmission error. The independent helix angle error has the strongest impact both on the contact pattern and transmission error, which is similar to the impact on the tooth surface deviations. However, the independent cone angle error shows less effects on the mesh characteristics.

\section{Acknowledgements}

The authors would like to thank the National Natural Science Foundation of China (Grant No. 51775061 and No. 51575060), China Postdoctoral Science Foundation (Grant No. 2015M582517) and Fundamental Research Funds for the Central Universities (2018CDQYJX0012).

\section{Reference}

Brecher, C., Brumm, M. and Henser, J., Validation of the tooth root load carrying capacity calculation of beveloid gears with parallel axes. Proceedings of International Gear Conference (France), (2014) August, pp.1038-1048.

Brecher, C., Löpenhaus, C. and Brimmers, J., Function-oriented Tolerancing of Tooth Flank Modifications of Beveloid Gears. Procedia CIRP, 14th CIRP Conference on Computer Aided Torlerancing, 43(2016), pp.124-129.

Bürkle, R., Gandbhir, S. and Joachim, F.J., Kegelige stirnräder zur leistungüber-tragung in getrieben (Conical gears for power transmission in gear units), VDI Report, 1056(1993), pp.95-110.

Chen, Q., et al., Manufacturing and contact characteristics analysis of internal straight beveloid gear pair, Mechanism and Machine theory,114(2017), pp.60-73.

Do, T. P., Ziegler, P. and Eberhard, P., Review on contact simulation of beveloid and cycloid gears and application of a modern approach to treat deformations. Mathematical and Computer Modelling of Dynamical Systems, Vol.21, No.4(2015), pp.359-388.

Hori, K., Hayashi, I. and Iwatsuki, N., The Ideal Tooth Profiles of Conical-External and internal gears meshing with cylindrical involute gears over the entire tooth width, Transactions of The Japan Society of Mechanical Engineers, Series C, Vol.41, No.4(1998), pp.901-911.

Koyama, G., Mitome, K. and Komatubara, H., Design of a pair of nonintersecting-nonparallel-axes conical involute gears having line contact tooth surface. Transactions of The Japan Society of Mechanical Engineers, 2005(2005), pp.206207.

Liu, C. C. and Tsay, C. B., Tooth undercutting of beveloid gears. Journal of Mechanical Design, Vol.123, No.4(2001), pp.569-576.

Liu, C. C. and Tsay, C. B., Contact characteristics of beveloid gears. Mechanism and Machine Theory, Vol.37, No.4(2002), pp.333-350.

Mitome, K., Inclining work-arbor taper hobbing of conical gear using cylindrical hob. Journal of Mechanisms, Transmissions, and Automation in Design, Vol.108, No.1(1986), pp.135-141.

Morikawa, K., Nagahara, M., Kumagai, K., Komori, M. and Matsumoto, S., Mesh efficiency analysis of conical involute gears. Transactions of the JSME, Vol.80, No.815(2014), pp.1-11.

Morikawa, K., Kumagai, K. and Nagahara, M., Influence of tooth flank modification on tooth surface damage of conical involute gears, Transactions of the Japan Society of Mechanical Engineers, Vol.81, No.829(2015), pp.1-8.

Ni, G., Zhu, C., Song, C., Du, X., Zhou, Y., Tooth contact analysis of crossed beveloid gear transmission with parabolic modification, Mechanism and Machine Theory, 113(2017), pp.40-52.

Ni, G., Zhu, C., Song, C. and Liu, H., Geometric design and meshing characteristics analysis of beveloid gear transmission with parallel axes, Hsi-An Chiao Tung Ta Hsueh/Journal of Xi'an Jiaotong University, Vol.50, No.5(2016), pp.57-64.

Somschor, B., Bürkle, R., Gandbhir, S. and Schulz, H., Conical gears in planetary gear transmission for industrial robots, VDI Report, 1230(1996), pp.473-489.

Wu, S. H. and Tsai, S. J., Contact stress analysis of skew conical involute gear drives in approximate line contact. Mechanism and Machine Theory, Vol.44, No.9(2009), pp.1658-1676.

$\mathrm{Wu}, \mathrm{S}$. H. and Tsai, S. J., Geometrical design of skew conical involute gear drives in approximate line contact. Proceedings of the Institution of Mechanical Engineers Part C-Journal of Mechanical Engineering Science, Vol.223, No.9(2009), 
Yang, Song, Zhu and Liu, Journal of Advanced Mechanical Design, Systems, and Manufacturing, Vol.12, No.4 (2018)

pp.2201-2211.

Zhu, C., Song, C., Lim, T. C. and Vijayakar, S., Geometry design and tooth contact analysis of crossed beveloid gears for marine transmissions. Chinese Journal of Mechanical Engineering, Vol.25, No.2(2012), pp.328-337. 